This is a preprint of the accepted peer-reviewed paper forthcoming in

Burr, C. \& Floridi, L. (Eds.) Ethics of Digital Well-Being: A

Multidisciplinary Approach. Springer Open.

\title{
Causal Network Accounts of Ill-being: Depression \& Digital Well-being
}

Nick Byrd

Florida State University

nick.a.byrd@gmail.com

\begin{abstract}
Depression is a common and devastating instance of ill-being which deserves an account. Moreover, the ill-being of depression is impacted by digital technology: some uses of digital technology increase such ill-being while other uses of digital technology increase well-being. So a good account of ill-being would explicate the antecedents of depressive symptoms and their relief, digitally and otherwise. This paper borrows a causal network account of well-being and applies it to ill-being, particularly depression. Causal networks are found to provide a principled, coherent, intuitively plausible, and empirically adequate account of cases of depression in everyday and digital contexts. Causal network accounts of illbeing also offer philosophical, scientific, and practical utility. Insofar as other accounts of ill-being cannot offer these advantages, we should prefer causal network accounts of ill-being.
\end{abstract}

Keywords. ethics, digital well-being, philosophy of science, causation, illbeing, depression

Acknowledgments. This paper was improved by Rachel Amoroso, Aaron Brooks, Chris Burr, Mike Bishop, Frances Fairbairn, Mary Marcous, Al Mele, Sam Sims, and anonymous reviewers. 


\section{Introduction}

Depression is not uncommon. Estimates suggest that major depressive disorder (MDD) affects more than 272 million people worldwide (Baxter et al., 2014, p. 509-510; US Census Bureau, 2011). And the ill-being of depression is not an isolated phenomena; many other forms of ill-being are comorbid with depression (Avenevoli, Swendson, He, Burnstein, \& Merikangas, 2015). So there is plenty of reason to understand instances of ill-being like depression. However, ill-being is complicated, making it difficult to capture the phenomena with a single account (Busseri \& Mise, 2019).

This paper proposes that causal networks can account for ill-being. It will focus mainly on the instance of depression and digital technology's role therein. The resources for this account of ill-being are borrowed from existing causal network accounts of well-being (Bishop, 2012, 2015). The present attempt will not amount to a complete account of ill-being, but it provides both a framework for a more complete account and as motivation to pursue the more complete account. Further, insofar as causal network accounts of ill-being complement existing causal network accounts of wellbeing, the present causal network account can be instrumental in a comprehensive account of welfare, digital and otherwise.

\section{Causal Networks}

Causal networks have a few parts: nodes, relationships, and fragments. Further, one and the same effect can be produced by different causal networks. So a causal network account of ill-being will explain ill-being as a multiply realizable phenomena that is realized by - among other thingsnodes, relationships, and fragments.

\subsection{Parts Of Networks}

Nodes. A node represents a single variable which has some causal relationship(s) with other variables in a network. One variable that seems to be causally related to ill-being is socio-economic status (SES) (Headey, Holmström, \& Wearing, 1984, 1985). So SES might be a node in ill-being networks.

Relationships. Nodes are connected to one or more other nodes in

a network - these connections are often called "edges" in the literature on 
causal modeling (e.g., Scheines, Spirtes, Glymour, Meek, \& Richardson, 1998). Nodes can have two kinds of connection with each other: promotional connections and inhibitory connections. Firstly, a node is in a promotional relationship with another node just in case an increase in the coefficient of the one node causes an increase in the coefficient of the other node. The promotional relationship is represented by the line ending with an arrow, as in Figure 1 (left), which represents an increase in SES causing an increase in self-esteem (ibid.).

Figure 1. Promotional relationship (left) and inhibitory relationship (right).
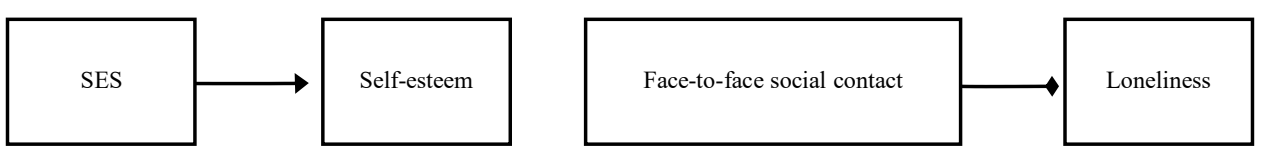

Secondly, a node is in an inhibitory relationship with another node just in case an increase in the coefficient in one node results in a decrease in the coefficient in the other node. The inhibitory relationship is represented by the line ending with a diamond as in Figure 1 (right), which represents an increase in face-to-face social contact causing a decrease in loneliness (Kross et al., 2013).

Fragments. A fragment is a non-complete portion of a network. More precisely, a network fragment refers to two or more nodes (of a network containing more than two nodes) as well as the relationships between these nodes.

\subsection{Properties Of Causal Networks}

Multiple realizability. We can distinguish between higher-level and lower-level states and changes. Lower-level states or changes in a network refer to states or changes to the structure and dynamic of a network. Higher-level states or changes in a network refer to states or changes that emerge from lower-level states or changes. For example, lower-level changes in SES, face-to-face social contact, and loneliness will have an impact on higher level states of ill-being such as self-esteem.

In this paper, "ill-being" refers to a higher-level phenomenon that emerges from the states and changes in the structure and dynamics of lowerlevel networks, which will be called ill-being networks. Notably, higherlevel network states can be multiply realizable. That is, two or more different lower-level network states might correspond to one state of illbeing. 
Individuation. If ill-being is multiply realizable, then individuating different instances of ill-being will sometimes require individuating the differences in the causal networks from which they emerged. Causal networks can be individuated by their structure and their dynamics.

Two networks have different structure when they have different nodes and/or different connections between nodes. For example, a network with three nodes can be individuated from networks containing more or less than three nodes. Similarly, two networks with the same nodes can be individuated if they do not share all the same connections between their nodes. So the network fragments above have different structure because they have different nodes.

Two networks have different dynamics when, all else being equal, the relationship between one network's nodes are non-identical to the relationships between another network's nodes. For instance, a network that contains only promotional relationships is distinct from a network of the same nodes that contains only inhibitory relationships. So the network fragments above have different dynamics because one has only a promotional relationship and the other has only an inhibitory relationship.

\section{A Causal Network Account of Ill-being}

With the basic resources of causal networks, we can begin to explain illbeing. To focus the discussion, we will limit our scope to cases of depression and digital well-being.

\subsection{Causal Networks \& Ill-being}

The first order of business is to point out that the overall dynamic of a causal network can be positive, negative, or neutral (Bishop 2015, p. 41). These dynamics determine whether the network is contributing to well-being or ill-being.

Causes of well-being and ill-being. A positive causal network is a network that inhibits ill-being or contributes to well-being (see also Bishop, 2015, p. 10-11). Conversely, a negative causal network would either inhibit well-being or contribute to ill-being.

Now consider ill-being. Ill-being involves many variables: feelings, beliefs, motivations, behaviors, habits, traits, abilities, goals, goalattainment, resources, and perhaps other variables. A causal network account of ill-being can represent these aspects of ill-being with nodes. 
Causal networks can also represent the relationships between variables. Ill-being involves many such relationships. For example, financial and social resources can causes changes in one's feelings and attitudes (Headey, Holmström, \& Wearing, 1985, p. 221).

Robustness of well-being and ill-being. Also, causal networks can be more or less robust - where 'robust' refers to the resilience of a higherlevel network state in the face of lower-level network changes. One's illbeing network is more robust insofar as more interventions on (lower-level) states of the ill-being network produce fewer changes to one's ill-being. Another way to say this is that the more one can change the structure and dynamic of the ill-being network without changing one's ill-being, the more robust their ill-being network is.

This notion of robustness implies that there will be (qualitative and quantitative) thresholds such that some threshold-breaking amount of change to the structure and/or dynamic of an ill-being network will result in a change in ill-being. In other words, once a threshold is broken, an otherwise robust negative causal network that was reinforcing ill-being might no longer reinforce ill-being.

\subsection{Depression \& Rumination}

Some people are more likely than others to believe that their happiness is a function of goal-attainment. Interestingly this belief is related to numerous other variables like the proclivity to ruminate and the risk of depression (McIntosh, 1996, McIntosh, Harlow, \& Martin, 1995; McIntosh \& Martin, 1992).

For illustration, consider two people: Lincoln and Jordan. Lincoln believes that happiness is linked to goal-attainment. Jordan doesn't believe this. Like anyone might, when Lincoln or Jordan realize that they have attained a goal, they briefly experience a positive feeling. And when they realize that they have failed to reach a goal, they briefly experience a negative feeling. However, because Lincoln believes that happiness is linked to goal-attainment, whenever Lincoln realizes that they failed to reach a goal, Lincoln ruminates about this failure. And the more Lincoln ruminates, the more Lincoln feels negatively. Only when Lincoln stops ruminating can they continue trying to attain the same goal. So, unless Lincoln disengages or attains the goal, Lincoln might become stuck in a cycle of negative feelings. Jordan, however, is not so prone to ruminate about failing to attain a goal. After all, Jordan doesn't believe that their 
happiness is related to attaining or failing to attain goals. So when Jordan fails to attain a goal, the effects are briefer and less negative.

In this example, one's beliefs and habits turn out to be crucial to illbeing. In this case, Lincoln has a belief about happiness and a habit of ruminating that Jordan didn't have. Both are importantly related to other nodes in the ill-being network such that when Lincoln encounters certain scenarios, they are more prone to fall into a negative cycle of rumination and negative feelings (Figure 2). In network terminology, the dynamics of Jordan and Lincoln's causal networks varied as a function of at least two variables: a particular belief and a particular habit.

Lincoln and Jordan are not alone. The effect of their beliefs about happiness and goal-attainment on their ill-being seems to be generalizable (McIntosh, 1996; McIntosh, Harlow, \& Martin, 1995; McIntosh \& Martin, 1992). And the effect of their rumination is also generalizable since it is associated with being in longer and more severe bouts of depression following stressful circumstances (Beck, 1970a, 1970b, 1979a, 1979b, 1991; Beck \& Greenburg, 1984; Beck, 1995; Millar, Tesser, \& Millar, 1988; Nolen-Hoeksema, 1991). In fact, rumination has also been posited as the mechanism that explains why some depressive risk-factors result in depression and others do not (Spasojević \& Alloy, 2001).

From these details about beliefs, goals, rumination, and negative affect, we can begin to see how a causal network might account for the illbeing of certain instances of depression. The causal network can also account for the self-reinforcing nature of certain instances of depression. Further, the causal network accounts for the difference in ill-being between two people that have similar experiences-e.g., similar goal-attainment.

\subsection{Depression \& Learned Helplessness}

These self-reinforcing dynamics of negative causal networks are helpful in understanding further features of ill-being like robustness. Consider learned helplessness. Learned helplessness is induced when a person finds themselves in an undesirable or painful circumstance so often that the person loses the motivation to avoid said circumstances (Abramson,

Seligman, \& Teasdale, 1978; Maier \& Seligman, 1976). Various investigations suggest that learned helplessness is a causal condition for depression (Peterson \& Seligman, 1984). 
Figure 2. Two causal network fragments adapted from McIntosh (1996, p. 65, Figure 3.1) illustrating how the same events can produce different levels of well-being or ill-being depending on beliefs.

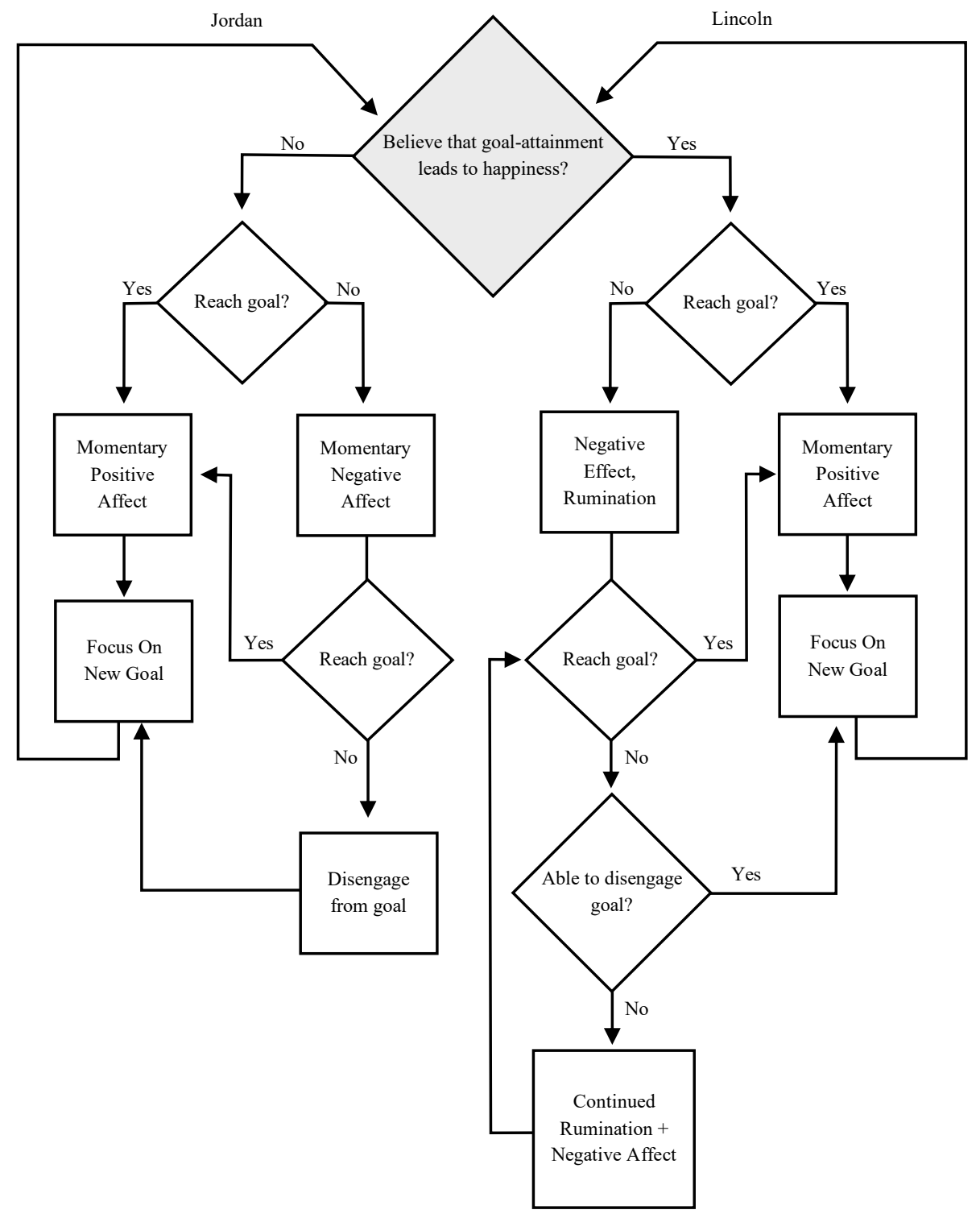

To illustrate how a certain negative causal network might lead to learned helplessness and thereby to depression, consider Jonsi. Jonsi believes - implicitly or explicitly - that their happiness is closely tied to excelling at work. So whenever Jonsi believes that they are doing poorly at work, Jonsi feels negatively. Further Jonsi has a habit of responding to negative feelings by ruminating on them, which leads to additional negative feelings. So doing poorly at work can quickly lead Jonsi's into a downward emotional spiral, which might culminate in learned helplessness. And if Jonsi is experiencing learned helplessness, then Jonsi's motivation becomes 
dangerously low. Some people can recover from this. They might, for example, have the resources to break the self-perpetuating cycle of rumination and negative effect by challenging the thoughts that are producing the negative feelings (e.g., cognitive-behavioral therapy) or by immersing oneself in experiences that supplant negative thoughts with neutral thoughts or positively valanced thoughts (e.g., a social gathering, a romantic evening, or an impromptu weekend getaway). But Jonsi doesn't have the financial or social resources for these strategies. Jonsi is a single parent with insufficient financial or social resources to take a break from their near-constant work and child-care responsibilities. So Jonsi's negative thoughts continue to reinforce their negative feelings and vice versa. In network terminology, the dynamic of Jonsi's ill-being network is becoming increasingly negative and increasingly robust. Soon Jonsi seems to lack motivation entirely. Most days Jonsi cannot even bear to leave the house. This results in poor attendance at work, which increases Jonsi's sense of not excelling at work. Eventually Jonsi's absenteeism becomes too much for their employer and Jonsi loses their job. Naturally, this makes Jonsi feel worse than ever about work and so Jonsi loses all hope that things will get better and begins wondering whether life is still worth living.

What was just described is a robust negative network fragment (Figure 3). It will be familiar to those who have experienced or witnessed severe cases of depression. At first, the negative dynamics of this causal network fragment might have been weakened by modest disruptions to the network-e.g., by changing Jonsi's beliefs about their vocation, by interrupting rumination, and/or by allowing Jonsi to enjoy some time away from vocational or child-care responsibilities, etc. But eventually the causal network's dynamic became increasingly negative and increasingly robust until modest interventions would no longer have an impact on Jonsi's illbeing. The network's change thresholds were just too high for such modest changes to cause a higher-level change in ill-being.

\subsection{Implications For Ill-being}

The causal roles of rumination and learned helplessness in depression are, of course, empirical hypotheses subject to empirical testing. Nonetheless, insofar as these causal network fragments adequately capture ill-being dynamics, they have implications for well-being-including digital wellbeing (Burr, Taddeo, \& Floridi, forthcoming). 
Figure 3. Ill-being network fragment.

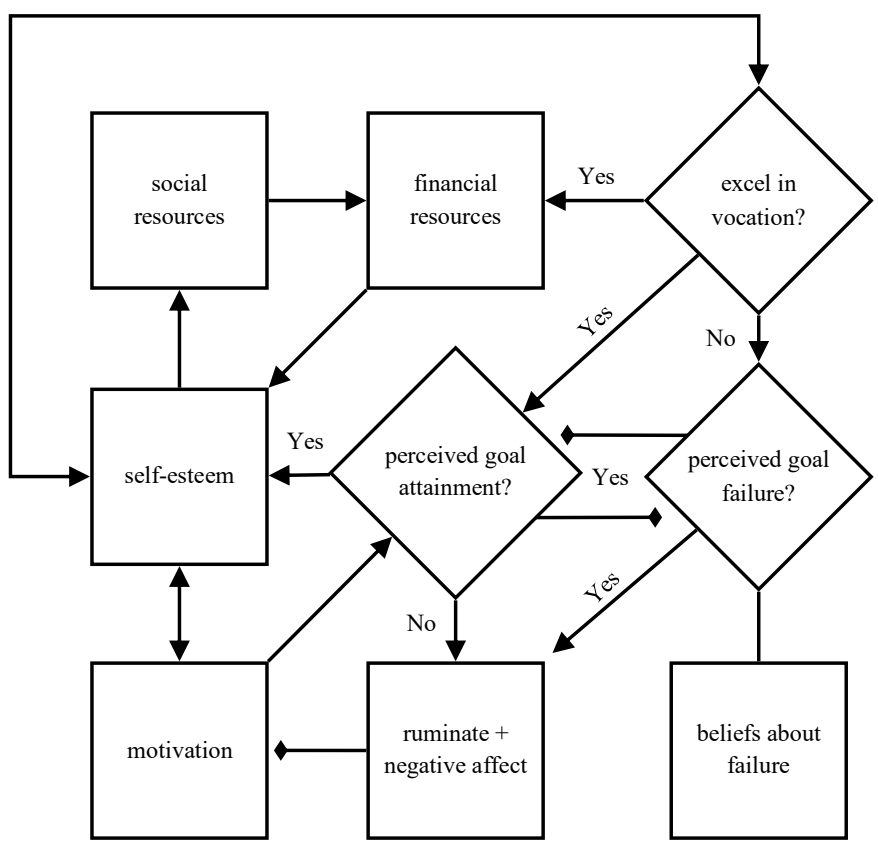

External nodes. Some nodes in Lincoln's, Jordan's, and Jonsi's well-being network fragments are external. That is, they are not part of one's body, one's immediate environment, or even one's domain of controllable factors (e.g., social resources, financial resources). This means that ill-being can depend on factors outside one's control (Headey, Holmström, \& Wearing, 1984, 1985). This is unsurprising. Loved ones die, accidents happen, economies crash, natural disasters occur, and so on. We usually cannot control these factors and yet can have significant impacts on our well-being.

Of course, institutions can control factors that many individuals cannot. So even if I cannot exert control over monetary, tax, and other policies, some institutions can. As such, some part of my well-being is decided by these institutions. Depending on the nature of responsibility, this might entail that such institutions are also responsible for some part of my well-being (Floridi, 2018). So causal network accounts of ill-being recommend investigation of potential institutional responsibilities for illbeing.

Digital ill-being. Some external factors are partially in our control. Consider digital technology. We can often choose how to use digital technology. Moreover, digital technology designers can often choose how to impact users well-being. 
Although some argue that digital technology is improving wellbeing (Schwab, 2017), others are less sanguine. Indeed, the World Health Organization recently recommended that children limit the use of digital technology in order to limit its detrimental impact on well-being (2019). Indeed, one observational study of a nationally representative sample of over a million US adolescent students found that using digital technology predicted lower well-being (Twenge, Martin, \& Campbell, 2018). More recent analyses suggest that using digital technology accounted for, at most, $0.4 \%$ of the variance in well-being (Orben \& Przybylski, 2019).

The actual impact of digital technology on well-being is an empirical question. Still, insofar as we think that ill-being networks contain nodes pertaining to digital technology and we want to better predict and control ill-being, there is reason to investigate and intervene on the relationship(s) between digital technology and ill-being (Peters, Calvo, \& Ryan, 2018).

Social networks. Some of the external nodes in a well-being or illbeing network are people (or features of other people). In other words, our welfare is at least partially dependent on other people.

There is some evidence that such social factors do influence our welfare. For instance, bullying predicts fewer friendships in early adolescence, which predicts depressive symptoms in later adolescence (Harmelen et al., 2016). Relatedly, family adversity in childhood predicts less family support in adolescence, which predicts greater depressive symptoms in later adolescence (ibid.).

There is also evidence that digital social networks can influence our welfare. For instance, passively consuming information about people in our digital social network is linked to lower subjective well-being; conversely, actively broadcasting and exchanging information with people in our digital social network is linked to higher subjective well-being (Verduyn, Ybarra, Résibois, Jonides, \& 2017).

Insofar as these social factors impact well-being and we want to better predict and control ill-being, we should study how these social factors feature in ill-being networks. Fortunately, some psychologists are already employing such network analyses (Aalbers, McNally, Heeren, de Wit, \& Fried, 2019). For instance, Faelens and colleagues' (2019) correlational network analyses found that social comparison and self-esteem featured centrally in networks of Facebook use, rumination, depressive symptoms, and other factors (Figure 4). 
Figure 4. Correlational networks (Faelens, Hoorelbeke, Fried, Raedt, \& Koster, 2019, Study 2). $\mathrm{COM}-\mathrm{F}=$ Comparison Orientation Measure-Facebook. $\mathrm{CSE}=$ contingent self-esteem. $\mathrm{CSS}=$ Contingent Self-Esteem Scale. FBI = Facebook Intensity Scale. MSFU = Multidimensional Scale of Facebook Use. RRS $=$ Ruminative Responses Scale. RSES $=$ Rosenberg Self-Esteem Scale. SNS = Social networking sites. DASS. Depression, Anxiety and Stress Scales.

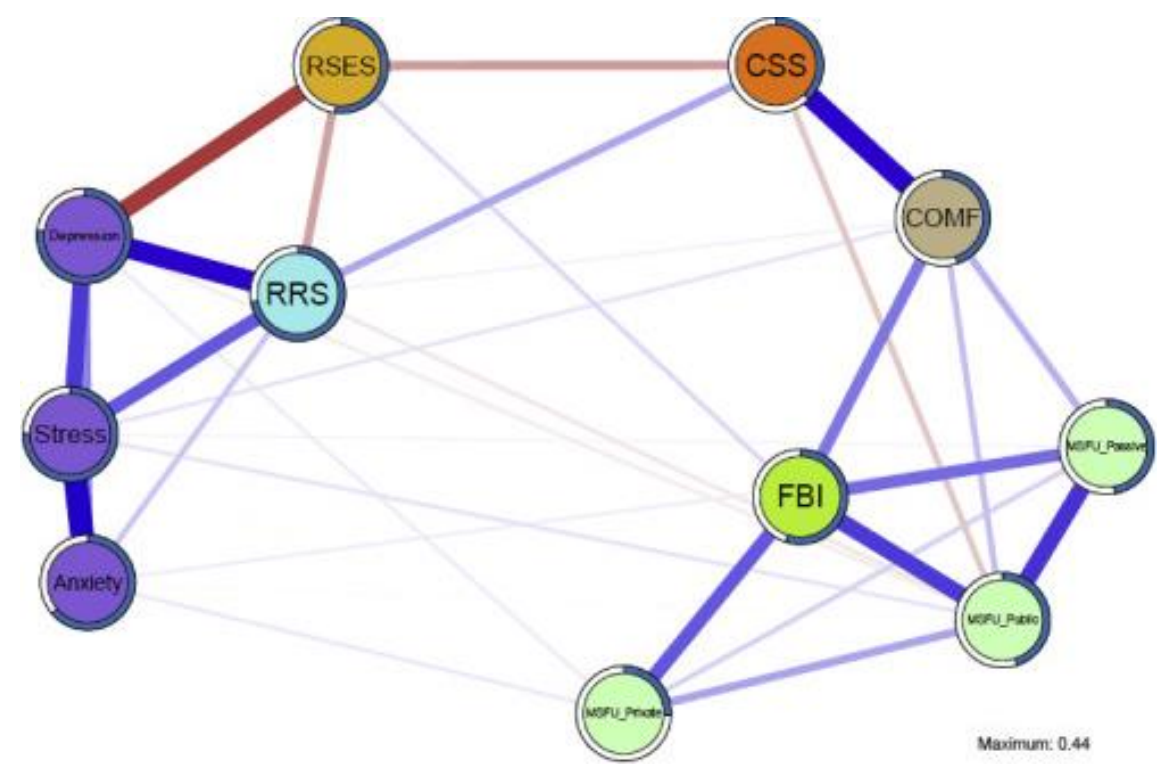

Self-reinforcement. Causal networks also capture the selfreinforcing nature of some kinds of ill-being. When something improves our mood, our better mood might thereby lift the moods of those round us. And this positive dynamic might be self-reinforcing. Alas, self-reinforcing dynamics can also be negative. When something puts us in a sour mood, we might thereby put others in a sour mood. All of this depends, of course, on how the nodes between various ill-being networks are related.

\subsection{Overview Of Causal Network Accounts Of Ill-being}

Causal networks offer a coherent, fruitful, and informative account of illbeing. The risk and induction of, say, depression can be explained in terms of causal network dynamics. Moreover, the treatment-resistance of depression can be explained in terms of the robustness of causal networks. Causal network analysis can also capture how online and offline social factors can contribute to ill-being. Of course, this is only a sketch of a causal network account of ill-being. A more complete causal network account of ill-being would address more features and instances of ill-being. To understand why one should invest in a causal network account of ill-being, we should consider the potential benefits to philosophy, science, and everyday life. 


\section{Benefits Of Network Accounts Of Ill-being}

One metric of the success of an account or concept is its utility (e.g., Dutilh Novaes, 2018; Haslanger, 2012; Shepherd \& Justus, 2015). Causal network accounts of ill-being offer philosophical, scientific, and practical utility.

\subsection{Philosophical Utility}

A causal network account of depression provides a framework for other forms of ill-being. Once other forms of ill-being are fit into a causal network account, we would have a complement to causal network accounts of wellbeing (e.g., Bishop, 2015). Once causal networks account for both ill-being and well-being, it would seem that causal networks account for welfare more generally. In other words, a causal network account of ill-being might be instrumental in a complete account of welfare. This provides some motivation to explore the potential of causal network accounts of ill-being.

Importantly, much of the grist for causal network accounts of illbeing is scientific. Philosophers' intuitions only take us so far. After all, when two intuitions conflict, we need a method for arbitrating between them (Bishop, 2015). One way to arbitrate between intuitions involves studying intuitions about ill-being as well as the psychological processes that produce these intuitions (Knobe \& Nichols, 2007). So experimental philosophy could be crucial to the advancement of ill-being research.

\subsection{Scientific Utility}

Imagine that you're deciding between two accounts of ill-being. Both accounts do well to capture our first-person experience and our intuitions about ill-being. But only one account unifies, makes sense of, and is useful to science. It seems that this latter account should be preferred to the account that offers only armchair purchase (Bishop, 2015; Kitcher, 1981; Woodward, 2014). There is some reason to think that a causal network account of ill-being is the second sort of account. Consider a range of evidence from science.

Science generally. By identifying two variables and intervening on one-while controlling other variables-scientists reveal causal relationships between two variables (Woodward, 2003; Saatsi \& Pexton, 2013). And since causal networks represent variables (as nodes) and the causal connections between variables, a causal network account of ill-being stands to unify otherwise disparate studies of the variables involved in illbeing. For example, suppose that some experiments find that using backlit 
touchscreens in the evening disrupts circadian rhythms and other experiments find that disrupting circadian rhythms disrupts self-esteem. These otherwise disparate findings could be unified with a causal network with nodes referring to evening backlit touchscreen use, circadian rhythm, and self-esteem.

Experimental psychology. Publications in experimental psychology about well-being are rife with causal models like the ones offered herein (Burnette, Davis, Green, Worthington, \& Bradfield, 2009, p. 277 Figure 1; Carnelly, Pietromo, \& Jaffe, 1994, p. 129 Figure 1; RadeckiBush, Farrel, \& Bush, 1993, pp. 573 Figure 1, 579 Figure 2, 580 Figure 3, 582 Figure 4; Tasca et al., 2009, p. 665, Figures 1 and 2; Tse \& Yip, 2009, p. 367, Figure 1). In fact, many of the causal models in the previous sections were adapted from the causal models of experimental psychologists. So it is no accident that the causal network account resembles this literature.

Neuroscience. Exercise has been widely shown to relieve depressive symptoms (Blumenthal et al., 1999; Cooney, Kerry, \& Gillian, 2014; Kramer \& Ericsson, 2007; Motl et al., 2005; Pedersen \& Saltin, 2015; Schuch et al., 2016). And neuroscience is providing, in broad strokes at least, some clues about the causal network(s) that account for these positive outcomes.

Exercise and regular physical activity seem to directly affect the brain in various ways. For instance, exercise and physical activity improve synaptic structure by improving potentiating synaptic strength (Cotman, Berchtold, \& Christie, 2007), improve neural plasticity via neurogenesis (ibid.), increase glia density (Spielman, Little, \& Klegeris, 2016), additional 5-HT and dopamine (ibid.), additional astrocytes at the blood-brain barrier (ibid.), increase signals of both glutamate and GABA in the visual cortex (Maddock, Casazza, Fernandez, \& Maddock, 2016), and increased signals of glutamate in the anterior cingulate cortex (ibid.). Effects like these are said to jointly cause "growth factor cascades" which improve overall "brain health and function" (Cotman, Berchtold, \& Christie, 2007; Kramer \& Ericsson, 2007).

Exercise and physical activity also indirectly affect the brain. Generally speaking, "exercise reduces peripheral risk factors for cognitive decline" by preventing - among other things-neurodegeneration, neurotrophic resistance, hypertension, and insulin resistance (Cotman, Berchtold, \& Christie, 2007; Prakash, Voss, Erickson, \& Kramer, 2015). By preventing these threats to neural and cognitive health, exercise is indirectly promoting conditions for brain health and function. And all of these direct 
and indirect effects of exercise and physical activity on the brain are associated with or causally related to significant reductions in depressive symptoms (Spielman, Little, \& Klegeris, 2016, pp. 22-23, 25-26).

We can represent these direct and indirect effects of exercise and physical activity on depression with a causal network fragment (Figure 5).

Figure 5. Exercise promotes outcomes in the brain that promote other positive outcomes outside the brain. Similarly, exercise reduces negatives outcomes that would reduce certain positive outcomes. This is adapted from causal network models from Cotman and colleagues' (2007) work and includes details from a review by Spielman and colleagues (2016).

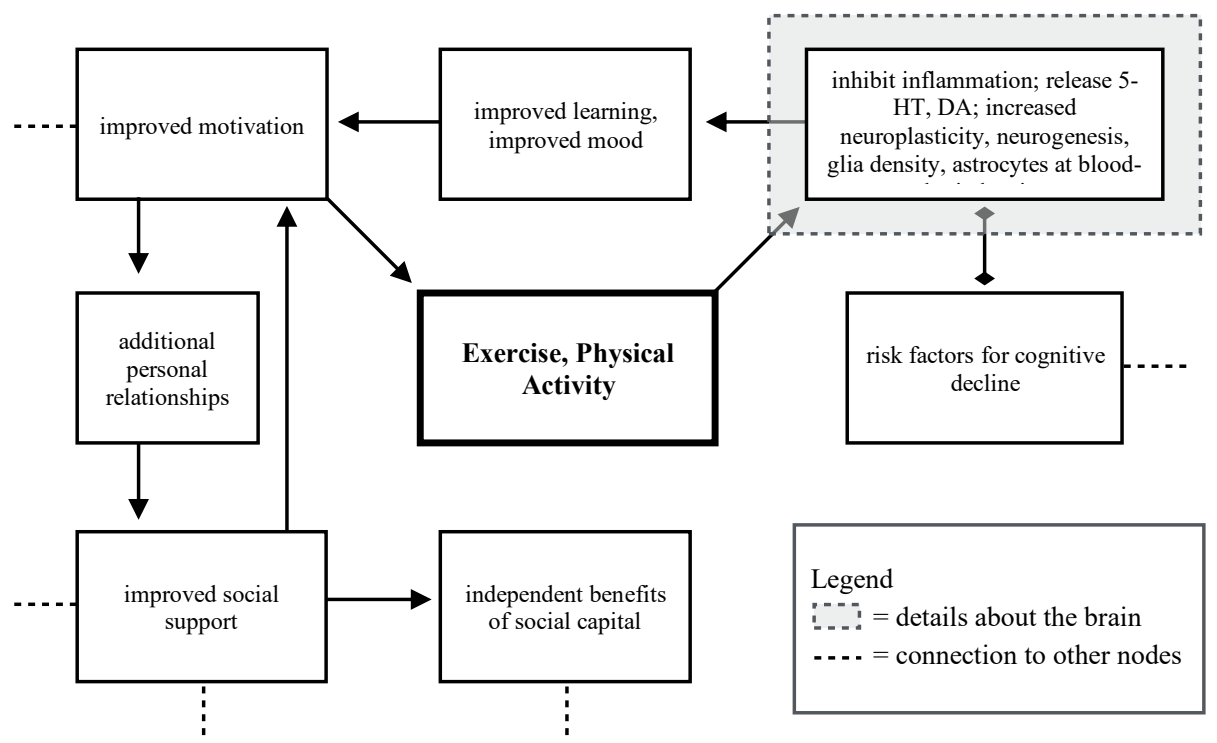

Exercise is not the only intervention on the brain that matters. Randomized experiments find that stimulating and/or disrupting neural function in various subcortical regions of the brain (e.g., deep brain stimulation or DBS) led to significant and long-term reductions in depressive symptoms (Bewernick et al., 2010; Lozano et al., 2008; Mayberg et al., 2005).

All of these hypotheses about the brain's relationship to cases of illbeing like depression seem amenable to a causal network account. Admittedly, more research is needed to identify all of the causally relevant variables and precisify the causal dynamic(s) in the brain which underlie various forms of ill-being like depression.

Economics. Economists and other social scientists also use causal networks to visualize their research on well-being. For example, it was economists who helped reveal that the effects of self-esteem and personal competence on health and overall welfare are partially accounted for by socioeconomic status (Headey, Holmström, and Wearing 1984, 1985). They 
illustrated their findings with causal networks. They started with a relatively small network fragment (Figure 6), but soon found evidence of a larger network (Figure 7).

Figure 6. Headey, Holstrom, \& Wearing 1984, 129, figure 1.

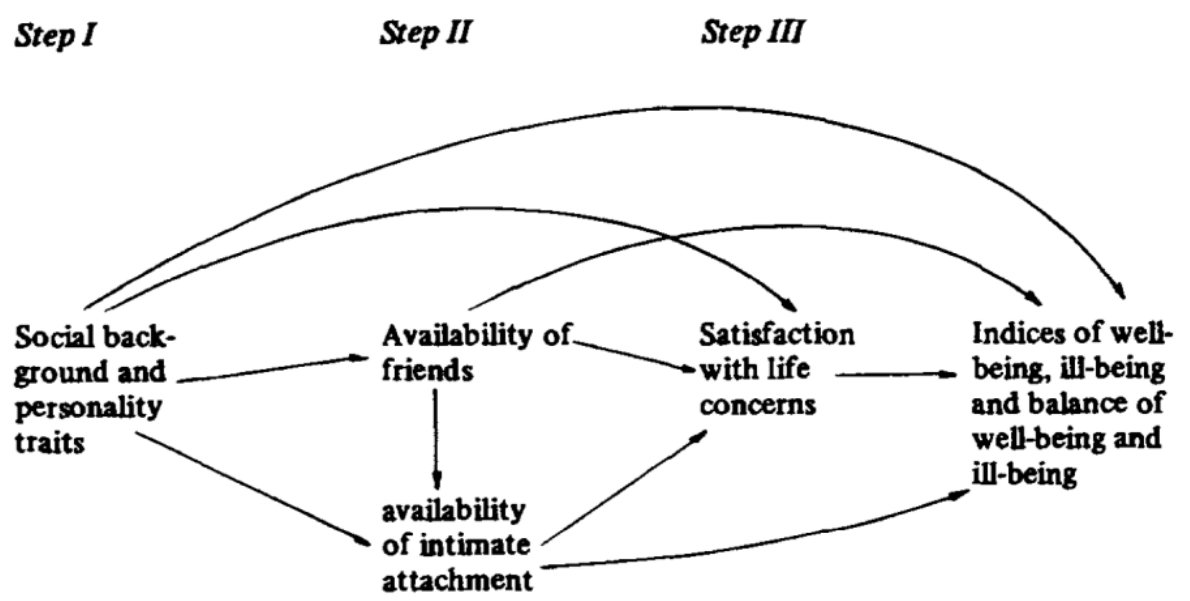

Fig. 1. Time sequence assumptions in analysis of causes of well-being and ill-being. (Variables not significant at the $5 \%$ level with any dependent variable have been omitted. Variables included in Table 111 but now omitted are sex, age, "Australian born" and "reliable alliances".)

Figure 7. Headey, Holstrom, \& Wearing 1985, 221, figure 1.

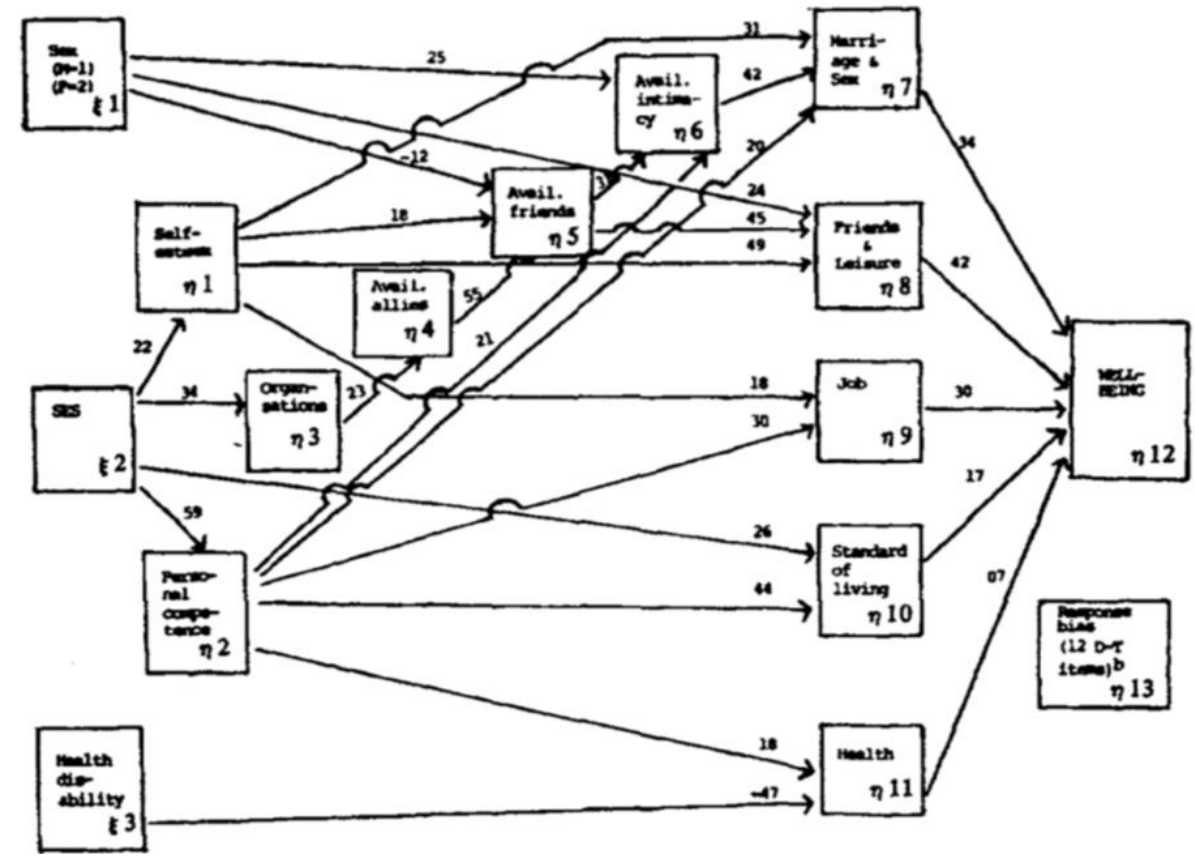

Psychiatry. Causal network accounts of ill-being also appear in psychiatry (e.g., Cramer \& Borsboom, 2015). Indeed, these accounts provide the 
resources to make sense of why depressive symptoms are relieved more reliably and for longer periods of time by certain manipulations like cognitive therapy (Gloaguen, Cottraux, Cucherat, \& Jordinburn. 1998; Ma \& Teasdale, 2004; Wampold, Minami, Baskin, \& Tierney, 2002), cognitivebehavioral therapy (CBT) (Tolin, 2010), and electroconvulsive therapy (ECT) (Tor et al., 2015). In fact, it was the literature in psychiatry that inspired the story of Jordan and Lincoln. This literature suggests thatamong other things - CBT's method of identifying and challenging certain negative, unhealthy, or even counterproductive beliefs can weaken negative causal network dynamics and thereby relieve depressive symptoms. These data suggest that - among other things - beliefs are part of many peoples' ill-being networks. The data also suggest that reflecting on our beliefs can have psychiatric benefits.

More recent meta-analysis have examined the efficacy of virtual versions of some of these therapies. They find that the virtual therapies are as effective as their non-virtual counterparts (Cheshman, Malouff, \& Schutte, 2018). This is one way that digital technology can be part of the solution to various cases of ill-being. In causal network terminology, the nodes referring to therapy could involve in vivo or virtual therapy.

Sports Medicine. Some have pointed out that eHealth technology might lead to greater adoption of physical activity regimens (Burr, Mariarosaria, \& Floridi, under review). Some evidence supports this hypothesis. For instance, a pre-registered randomized controlled trial found that activity tracker use stemmed reductions in moderate-to-vigorous physical relative to a control group 6 months after the experiment ended (Finkelstein et al., 2016). Although activity tracking often improves physical activity and mobility - which might reduce ill-being in various ways - their effects on quality of life is not well understood (Oliveira, Sherrington, Zheng, Franco, \& Tiedemann, 2019). Further research could clarify this part of causal networks involving activity, digital activity tracking, and well-being.

Other Sciences. Other domains of science reveal additional details about the network of causes that account for forms of ill-being like depression. For instance, depression seems to be causally related to genetic variation (Okbay et al., 2016), genetic expression (Gujral, Manuck, Ferrell, Flory, \& Ericsson, 2014), opioid activity (Hsu et al., 2015), and endogenous cytokine production (Müller et al., 2006).

Correlational Studies. Some scientific findings about ill-being are correlational rather than causal. For instance, depressive symptoms 
correlate with race (Weaver, Himle, Taylor, Matusko, \& Ableson, 2015), urban (vs. suburban) residence (ibid.; see also Anderson, 2010), endogenous protein production (Kahndaker, Pearson, Zammit, Lewis, \& Blanche, 2014), and vitamin D efficiency (Kerr et al., 2015). While correlational studies do not reveal causes, they reveal details which guide follow-up studies that might identify causes. So correlational studies are still amenable and instrumental to causal network accounts of ill-being and the science thereof.

\subsection{Practical Utility}

As philosophers continue to explicate the nodes in ill-being networks and scientists investigate their causal relationship to other nodes, we can better predict and control ill-being. Importantly, this philosophical and scientific work can be useful beyond philosophy and science. It can also serve ordinary people and institutions.

Institutions. Consider how governments and businesses might make use of the insights of scientific interventions on ill-being. First, they might be able to inform and reform policies that reliably inhibit their constituents' ill-being. Moreover, institutions might have the ability to intervene on nodes in people's ill-being networks in ways that individuals cannot. Thus, individuals might be reliant on institutions for certain interventions on their ill-being. Given this relationship, one might wonder if institutions owe it to their constituents to understand the causal networks involved in ill-being and implement policy accordingly.

Intervening on constituents' ill-being networks need not be entirely altruistic. Indeed, institutions might find that they can nudge constituents toward greater well-being in mutually beneficial ways (Conly, 2012). For instance, businesses might find that returns on investments increase as a result of employer-subsidized ill-being interventions. Indeed, businesses might already be crunching these numbers (Hargrave \& Hiatt, 2005; Hargrave, Hiatt, Alexander, \& Schaffer, 2008; McLeod, 2010; McLeod \& Mcleod, 2001; Stewart, Ricci, Chee, Hahn, \& Morganstein, 2003).

Individuals. Causal network accounts of ill-being can also deliver practical advice. Recall that various forms of physical activity, exercise, and therapy reliably inhibit certain forms of ill-being like depression and cognitive decline. It does not strain imagination to conceive of how people might use this knowledge to intervene on instances of ill-being.

This raises questions about how to think about failures to learn from and apply causal network accounts of well-being. Are we personally 
responsible for intervening on our own ill-being? Such universal responsibility seems difficult to defend. There are many reasons why we could know about interventions that will reliably inhibit our ill-being, fail to implement the intervention, and yet not be responsible (or blameworthy) for failing to implement these interventions-e.g., Jonsi's case of learned helplessness.

Nonetheless, our ill-being may have impacts on others'. So insofar as we have duties to not harm others' well-being, we might have duties to limit our own ill-being or its impact on others. Causal network accounts need not commit to positions about personal responsibility. The point is just that causal networks provide resources for identifying or tracing responsibility between individuals (Dennett, 2015).

\section{Objections \& Replies}

Causal network accounts of ill-being offer philosophical, scientific, and practical benefits. So causal network accounts should be preferred to accounts of ill-being that offer less than this. Nonetheless, the causal network theorist may encounter objections. Consider some objections related to normativity, triviality, intuitive appeal, and completeness.

\subsection{Normativity}

Some might complain that the causal network account of ill-being doesn't actually capture what is bad about ill-being. It doesn't account for why we should avoid ill-being and be concerned about others' avoiding ill-being. In other words, the causal network account of ill-being does not meet the "normativity requirement" (Bishop, 2015, p. 198).

The normativity requirement has many forms. Michael Bishop offers five possible ways to interpret the normativity requirement and then explains why it is not clear that any of the interpretations of the requirement are devastating to the causal network account of well-being (2015, pp. 198207). Since the causal network account of ill-being is based, in large part, on Bishop's causal network account of well-being, there is prima facie reason to think that Bishop's responses to the normativity requirement apply to the present account of ill-being as well. So unless it becomes clear that the normativity requirement is uniquely devastating to the present account of ill-being, further responses to the normativity requirement need not be invented. 
So consider Bishop's conclusion about normativity. First, we can agree on two outcomes: a causal network account either meets the normativity requirement or it doesn't. If it does meet the requirement, then the complaint about normativity is moot. If it doesn't meet the requirement, then there are at least two reasons why this failure might not be devastating: (a) the normativity requirement is illegitimate or (b) the normativity requirement is too controversial to constitute a universal requirement (Bishop, 2015, p. 207). So invoking the normativity requirement evokes two further requirements: (1) a legitimate and uncontroversial standard and (2) an explanation of precisely how the causal network account fails to meet this standard. Until these goods are delivered, causal networks accounts of ill-being will be unscathed by normativity requirements.

\subsection{We Knew It All Along}

Someone might also complain that the causal network account of ill-being is trivial in the following way. "Of course ill-being is the result of causal networks! Why would we have thought otherwise?"

One might say something even more detailed: the very fact that the causal network account is (i) intuitively plausible, (ii) implicit in scientific practice, (iii) inferred from various empirical findings, and it (iv) is not already formalized is reason to think that we have known about the causal network account all along, at least implicitly. If this is really what it means for something to be known all along, then so be it. It is not clear that that is a real problem for the causal network account of ill-being.

To illustrate, reconsider the complaint. If the causal network accounts of ill-being are so obvious, then it might be strange that no one has formalized such an account. After all, many scholars are in the business of - among other things - formalizing and tidying up our implicit, intuitive views about the world. So if a scholar provides a more formal and explicit version of our intuitive, implicit understanding, then they have not made an error. On the contrary, they have delivered the goods.

\subsection{Intuition Fitting}

Someone might also complain that causal network accounts of ill-being do not capture all of their intuitions about ill-being. The response to this complaint is simple: Satisfying every intuition is not an achievable standard. Further, it is not clear that satisfying every intuition is a good standard. Indeed, many instances of good scholarship seem to challenge the most common or potent intuitions. 
At this point, causal network accounts of ill-being seem to provide a coherent and compelling account of many intuitions about cases of illbeing-e.g., Lincoln's rumination and Jonsi's learned helplessness.

A complainant might reply as follows: "But lots of philosophical accounts capture some of our intuitions. How is the causal network account any better than the other philosophical accounts?" The answer to this question, of course, depends on the details of the alternative accounts. Causal network accounts of ill-being do more than just capture our intuitions. They also provide philosophical, scientific, and practical utility. If there are competing accounts of ill-being that can deliver all of these goods, then the complainant's point is well-taken. If, however, alternative accounts of ill-being do not deliver all of these goods, then causal network accounts seem to be preferable.

\subsection{Completeness}

Another complaint is that the present attempt to bolster causal network accounts of ill-being is incomplete. After all, this paper focuses on just a couple instance of ill-being: depression and digital ill-being. It does not catalog and account for every instance of ill-being. So it certainly does not follow from anything in this paper that ill-being, generally speaking, is wellcaptured by causal networks. This complaint seems reasonable.

Still, the friend of the causal network account might hope that the present account, while incomplete, provides a framework for more complete causal network accounts of ill-being. One framework that is implicit in this paper can be made explicit as follows: (A) identify instances of ill-being and then (B) appeal to first-personal and third-personal observations to propose which nodes might be involved in such ill-being; (C) provide empirically tractable explications of these nodes and their relationships; (D) test correlational and causal relationships between these nodes; (E) once some nodes and their relationships have been discovered, hypothesize the causal network fragment and its implications; (F) test the implications of the hypothetical causal network fragment; $(\mathrm{G})$ guide philosophical, scientific, and practical endeavors according to successful hypotheses about ill-being causal network fragments; $(\mathrm{H})$ compare the causal network accounts of ill-being to competing accounts to determine which account delivers more utility. So while the present account does not constitute a complete account of ill-being, it may be instrumental in a more complete account. 


\section{Conclusion}

Causal network accounts of depression and digital ill-being offer a framework for a more complete account of ill-being. Causal network accounts of ill-being also provide motivation to pursue this more complete account: philosophical, scientific, and practical utility. Further, insofar as the more complete causal network account of ill-being would complement an existing causal network account of well-being, causal network accounts are instrumental to a unified and complete account of welfare, digital and otherwise. Insofar as the alternative accounts of ill-being cannot do all of this, we should prefer causal network accounts of ill-being.

\section{Works Cited}

Aalbers, G., McNally, R. J., Heeren, A., de Wit, S., \& Fried, E. I. (2019). Social media and depression symptoms: A network perspective. Journal of Experimental Psychology: General, 148(8), 1454-1462. DOI: $10.1037 / x g e 0000528$

Abramson, L. Y., Seligman, M. E., \& Teasdale, J. D. (1978). Learned helplessness in humans: Critique and reformulation. Journal of Abnormal Psychology, 87(1), 49-74. DOI: 10.1037/0021843X.87.1.49

Anderson, E. (2010). The imperative of integration. Princeton University Press.

Avenevoli, S., Swendsen, J., He, J.-P., Burstein, M., \& Merikangas, K. R. (2015). Major Depression in the National Comorbidity SurveyAdolescent Supplement: Prevalence, Correlates, and Treatment. Journal of the American Academy of Child \& Adolescent Psychiatry, 54(1), 37-44.e2. DOI: 10.1016/j.jaac.2014.10.010

Baxter, A. J., Scott, K. M., Ferrari, A. J., Norman, R. E., Vos, T., \& Whiteford, H. A. (2014). Challenging the Myth of an "Epidemic" of Common Mental Disorders: Trends in the Global Prevalence of Anxiety and Depression Between 1990 and 2010. Depression and Anxiety, 31(6), 506-516. DOI: 10.1002/da.22230

Beck, A. T. (1970a). Cognitive therapy: Nature and relation to behavior therapy. Behavior Therapy, 1(2), 184-200. DOI: 10.1016/S00057894(70)80030-2

Beck, A. T. (1970b). Depression: Causes and Treatment. University of Pennsylvania Press.

Beck, A. T. (1979a). Cognitive Therapy and the Emotional Disorders. Penguin.

Beck, A. T. (1979b). Cognitive Therapy of Depression. Guilford Press. 
Beck, A. T. (1991). Cognitive therapy: A 30-year retrospective. American Psychologist, 46(4), 368-375. DOI: 10.1037/0003-066X.46.4.368

Beck, A. T., \& Greenberg, R. L. (1984). Cognitive Therapy in the Treatment of Depression. In N. Hoffman (Ed.), Foundations of Cognitive Therapy (pp. 155-178). Springer US. Retrieved from DOI: 10.1007/978-1-4613-2641-0_7

Beck, J. S. (1995). Cognitive Therapy: Basics and Beyond. Guilford Press.

Bewernick, B. H., Hurlemann, R., Matusch, A., Kayser, S., Grubert, C., Hadrysiewicz, B., ... Schlaepfer, T. E. (2010). Nucleus Accumbens Deep Brain Stimulation Decreases Ratings of Depression and Anxiety in Treatment-Resistant Depression. Biological Psychiatry, 67(2), 110-116. DOI: 10.1016/j.biopsych.2009.09.013

Bishop, M. (2012). The Network Theory of Well-being: An Introduction. The Baltic International Yearbook of Cognition, Logic and Communication, 7(1).

Bishop, M. (2015). The Good Life: Unifying The Philosophy and Psychology of Well-being. Oxford: Oxford University Press.

Blumenthal, J. A., Babyak, M. A., Moore, K. A., Craighead, W. E., Herman, S., Khatri, P., ... others. (1999). Effects of exercise training on older patients with major depression. Archives of Internal Medicine, 159(19), 2349-2356.

Burnette, J. L., Davis, D. E., Green, J. D., Worthington Jr., E. L., \& Bradfield, E. (2009). Insecure attachment and depressive symptoms: The mediating role of rumination, empathy, and forgiveness. Personality and Individual Differences, 46(3), 276-280. DOI: 10.1016/j.paid.2008.10.016

Burr, C., Taddeo, M., \& Floridi, L. (forthcoming). The Ethics of Digital Well-Being: A Thematic Review. In Burr, C. \& Floridi, L. (Eds.) Ethics of Digital Well-Being: A Multidisciplinary Approach. Springer Open.

Busseri, M. A., \& Mise, T.-R. (2019). Bottom-up or top-down? Examining global and domain-specific evaluations of how one's life is unfolding over time. Journal of Personality. DOI: 10.1111/jopy.12499

Conly, S. (2012). Against Autonomy: Justifying Coercive Paternalism. Cambridge: Cambridge University Press.

Cooney, G. M., Dwan, K., Greig, C. A., Lawlor, D. A., Rimer, J., Waugh, F. R., ... Mead, G. E. (2013). Exercise for depression. In The Cochrane Collaboration (Ed.), Cochrane Database of Systematic Reviews. Chichester, UK: John Wiley \& Sons, Ltd. Retrieved from DOI: 10.1002/14651858.CD004366.pub6

Cramer, A. O. J., \& Borsboom, D. (2015). Problems Attract Problems: A Network Perspective on Mental Disorders. In Emerging Trends in 
the Social and Behavioral Sciences. Retrieved from DOI: 10.1002/9781118900772.etrds0264/abstract

Dennett, D. C. (2015). Elbow Room: The Varieties of Free Will Worth Wanting. MIT Press.

Dutilh Novaes, C. (2018). Carnapian explication and ameliorative analysis: A systematic comparison. Synthese, 1-24. DOI: 10.1007/s11229018-1732-9

Faelens, L., Hoorelbeke, K., Fried, E., De Raedt, R., \& Koster, E. H. W. (2019). Negative influences of Facebook use through the lens of network analysis. Computers in Human Behavior, 96, 13-22. DOI: 10.1016/j.chb.2019.02.002

Finkelstein, E. A., Haaland, B. A., Bilger, M., Sahasranaman, A., Sloan, R. A., Nang, E. E. K., \& Evenson, K. R. (2016). Effectiveness of activity trackers with and without incentives to increase physical activity (TRIPPA): A randomised controlled trial. The Lancet Diabetes \& Endocrinology, 4(12), 983-995. DOI: 10.1016/S2213$8587(16) 30284-4$

Floridi, L. (2018). Soft Ethics and the Governance of the Digital. Philosophy \& Technology, 31(1), 1-8. DOI: 10.1007/s13347-0180303-9

Gloaguen, V., Cottraux, J., Cucherat, M., \& Ivy-Marie Jordinburn. (1998). A meta-analysis of the effects of cognitive therapy in depressed patients. Journal of Affective Disorders, 49(1), 59-72. DOI: 10.1016/S0165-0327(97)00199-7

Gujral, S., Manuck, S. B., Ferrell, R. E., Flory, J. D., \& Erickson, K. I. (2014). The BDNF Val66Met polymorphism does not moderate the effect of self-reported physical activity on depressive symptoms in midlife. Psychiatry Research, 218(1-2), 93-97. DOI: 10.1016/j.psychres.2014.03.028

Hargrave, G. E., \& Hiatt, D. (2005). The EAP Treatment of Depressed Employees. Employee Assistance Quarterly, 19(4), 39-49. DOI: 10.1300/J022v19n04_03

Hargrave, G. E., Hiatt, D., Alexander, R., \& Shaffer, I. A. (2008). EAP Treatment Impact on Presenteeism and Absenteeism: Implications for Return on Investment. Journal of Workplace Behavioral Health, 23(3), 283-293. DOI: 10.1080/15555240802242999

Harmelen, A.-L. van, Gibson, J. L., Clair, M. C. S., Owens, M., Brodbeck, J., Dunn, V., ... Goodyer, I. M. (2016). Friendships and Family Support Reduce Subsequent Depressive Symptoms in At-Risk Adolescents. PLOS ONE, 11(5), e0153715. DOI: 10.1371/journal.pone.0153715

Haslanger, S. (2012). Resisting Reality: Social Construction and Social Critique. Oxford University Press. 
Headey, B., Holmström, E., \& Wearing, A. (1984). Well-being and illbeing: Different dimensions? Social Indicators Research, 14(2), 115-139. DOI: 10.1007/BF00293406

Headey, B., Holmström, E., \& Wearing, A. (1985). Models of well-being and ill-being. Social Indicators Research, 17(3), 211-234. DOI: 10.1007/BF00319311

Hsu, D. T., Sanford, B. J., Meyers, K. K., Love, T. M., Hazlett, K. E., Walker, S. J., ... Zubieta, J.-K. (2015). It still hurts: altered endogenous opioid activity in the brain during social rejection and acceptance in major depressive disorder. Molecular Psychiatry, 20(2), 193-200. DOI: 10.1038/mp.2014.185

Khandaker, G. M., Pearson, R. M., Zammit, S., Lewis, G., \& Jones, P. B. (2014). Association of Serum Interleukin 6 and C-Reactive Protein in Childhood With Depression and Psychosis in Young Adult Life. JAMA Psychiatry, 71(10), 1121-1128. DOI: 10.1001/jamapsychiatry.2014.1332

Kerr, D. C. R., Zava, D. T., Piper, W. T., Saturn, S. R., Frei, B., \& Gombart, A. F. (2015). Associations between vitamin D levels and depressive symptoms in healthy young adult women. Psychiatry Research, 227(1), 46-51. DOI: 10.1016/j.psychres.2015.02.016

Kitcher, P. (1981). Explanatory unification. Philosophy of Science, 507531.

Knobe, J., \& Nichols, S. (2007). An Experimental Philosophy Manifesto. In J. Knobe \& S. Nichols (Eds.), Experimental Philosophy (pp. 314). Oxford University Press.

Kramer, A. F., \& Erickson, K. I. (2007). Capitalizing on cortical plasticity: influence of physical activity on cognition and brain function. Trends in Cognitive Sciences, 11(8), 342-348. DOI: 10.1016/j.tics.2007.06.009

Kross, E., Verduyn, P., Demiralp, E., Park, J., Lee, D. S., Lin, N., ... Ybarra, O. (2013). Facebook Use Predicts Declines in Subjective Wellbeing in Young Adults. PLoS ONE, 8(8), e69841. DOI: 10.1371/journal.pone.0069841

Lozano, A. M., Mayberg, H. S., Giacobbe, P., Hamani, C., Craddock, R. C., \& Kennedy, S. H. (2008). Subcallosal Cingulate Gyrus Deep Brain Stimulation for Treatment-Resistant Depression. Biological Psychiatry, 64(6), 461-467. DOI: 10.1016/j.biopsych.2008.05.034

Maier, S. F., \& Seligman, M. E. (1976). Learned helplessness: Theory and evidence. Journal of Experimental Psychology: General, 105(1), 346. DOI: $10.1037 / 0096-3445.105 .1 .3$

Ma, S. H., \& Teasdale, J. D. (2004). Mindfulness-Based Cognitive Therapy for Depression: Replication and Exploration of Differential Relapse Prevention Effects. Journal of Consulting and Clinical Psychology, 72(1), 31-40. DOI: 10.1037/0022-006X.72.1.31 
Mayberg, H. S., Lozano, A. M., Voon, V., McNeely, H. E., Seminowicz, D., Hamani, C., ... Kennedy, S. H. (2005). Deep Brain Stimulation for Treatment-Resistant Depression. Neuron, 45(5), 651-660. DOI: 10.1016/j.neuron.2005.02.014

McIntosh, W. (1996). When does goal nonattainment lead to negative emotional reactions, and when doesn't it?: The role of linking and rumination. Striving and Feeling: Interactions among Goals, Affect, and Self-Regulation, 53-77.

McIntosh, W. D., Harlow, T. F., \& Martin, L. L. (1995). Linkers and Nonlinkers: Goal Beliefs as a Moderator of the Effects of Everyday Hassles on Rumination, Depression, and Physical Complaints 1. Journal of Applied Social Psychology, 25(14), 1231-1244. DOI: 10.1111/j.1559-1816.1995.tb02616.x

McIntosh, W. D., \& Martin, L. L. (1992). The cybernetics of happiness: The relation of goal attainment, rumination, and affect. Review of Personality and Social Psychology, 222-246.

McLeod, J. (2010). The effectiveness of workplace counselling: A systematic review. Counselling and Psychotherapy Research, 10(4), 238-248. DOI: 10.1080/14733145.2010.485688

McLeod, J., \& McLeod, J. (2001). How effective is workplace counselling? A review of the research literature. Counselling and Psychotherapy Research, 1(3), 184-190. DOI: 10.1080/14733140112331385060

Millar, K. U., Tesser, A., \& Millar, M. G. (1988). The effects of a threatening life event on behavior sequences and intrusive thought: A self-disruption explanation. Cognitive Therapy and Research, 12(5), 441-457. DOI: 10.1007/BF01173412

Motl, R. W., Konopack, J. F., McAuley, E., Elavsky, S., Jerome, G. J., \& Marquez, D. X. (2005). Depressive Symptoms Among Older Adults: Long-Term Reduction After a Physical Activity Intervention. Journal of Behavioral Medicine, 28(4), 385-394. DOI: 10.1007/s10865-005-9005-5

Müller, N., Schwarz, M. J., Dehning, S., Douhe, A., Cerovecki, A., Goldstein-Müller, B., ... Riedel, M. (2006). The cyclooxygenase-2 inhibitor celecoxib has therapeutic effects in major depression: results of a double-blind, randomized, placebo controlled, add-on pilot study to reboxetine. Molecular Psychiatry, 11(7), 680-684. DOI: $10.1038 /$ sj.mp.4001805

Nolen-Hoeksema, S. (1991). Responses to depression and their effects on the duration of depressive episodes. Journal of Abnormal Psychology, 100(4), 569-582.

Oliveira, J. S., Sherrington, C., Zheng, E. R. Y., Franco, M. R., \& Tiedemann, A. (2019). Effect of interventions using physical activity trackers on physical activity in people aged 60 years and 
over: A systematic review and meta-analysis. British Journal of Sports Medicine. DOI: 10.1136/bjsports-2018-100324

Orben, A., \& Przybylski, A. K. (2019). The association between adolescent well-being and digital technology use. Nature Human Behaviour, 3(2), 173-182. DOI: 10.1038/s41562-018-0506-1

Okbay, A., Baselmans, B. M. L., De Neve, J.-E., Turley, P., Nivard, M. G., Fontana, M. A., ... Cesarini, D. (2016). Genetic variants associated with subjective well-being, depressive symptoms, and neuroticism identified through genome-wide analyses. Nature Genetics, advance online publication. DOI: $10.1038 / \mathrm{ng} .3552$

Pedersen, B. K., \& Saltin, B. (2015). Exercise as medicine - evidence for prescribing exercise as therapy in 26 different chronic diseases. Scandinavian Journal of Medicine \& Science in Sports, 25, 1-72. DOI: $10.1111 / \mathrm{sms} .12581$

Peters, D., Calvo, R. A., \& Ryan, R. M. (2018). Designing for Motivation, Engagement and Wellbeing in Digital Experience. Frontiers in Psychology, 9. DOI: 10.3389/fpsyg.2018.00797

Peterson, C., \& Seligman, M. E. (1984). Causal explanations as a risk factor for depression: Theory and evidence. Psychological Review, 91(3), 347-374. DOI: 10.1037/0033-295X.91.3.347

Prakash, R. S., Voss, M. W., Erickson, K. I., \& Kramer, A. F. (2015). Physical Activity and Cognitive Vitality. Annual Review of Psychology, 66(1), 769-797. DOI: 10.1146/annurev-psych-010814015249

Radecki-Bush, C., Farrell, A. D., \& Bush, J. P. (1993). Predicting Jealous Responses: The Influence of Adult Attachment and Depression on Threat Appraisal. Journal of Social and Personal Relationships, 10(4), 569-588. DOI: 10.1177/0265407593104006

Saatsi, J., \& Pexton, M. (2013). Reassessing Woodward's Account of Explanation: Regularities, Counterfactuals, and Noncausal Explanations. Philosophy of Science, 80(5), 613-624.

Scheines, R., Spirtes, P., Glymour, C., Meek, C., \& Richardson, T. (1998). The TETRAD Project: Constraint Based Aids to Causal Model Specification. Multivariate Behavioral Research, 33(1), 65-117. DOI: $10.1207 / \mathrm{s} 15327906 \mathrm{mbr} 3301 \_3$

Schuch, F. B., Deslandes, A. C., Stubbs, B., Gosmann, N. P., Silva, C. T. B. da, \& Fleck, M. P. de A. (2016). Neurobiological effects of exercise on major depressive disorder: A systematic review. Neuroscience \& Biobehavioral Reviews, 61, 1-11. DOI: 10.1016/j.neubiorev.2015.11.012

Schwab, K. (2017). The Fourth Industrial Revolution. Crown Publishing Group. 
Shepherd, J., \& Justus, J. (2015). X-Phi and Carnapian Explication. Erkenntnis, 80, 381-402. https://doi.org/10.1007/s10670-014-96483

Spasojević, J., \& Alloy, L. B. (2001). Rumination as a common mechanism relating depressive risk factors to depression. Emotion, 1(1), 25-37. DOI: $10.1037 / 1528-3542.1 .1 .25$

Stewart, W. F., Ricci, J. A., Chee, E., Hahn, S. D., \& Morganstein, D. (2003). Cost of lost productive work time among us workers with depression. JAMA, 289(23), 3135-3144. DOI: 10.1001/jama.289.23.3135

Tasca, G. A., Szadkowski, L., Illing, V., Trinneer, A., Grenon, R., Demidenko, N., ... Bissada, H. (2009). Adult attachment, depression, and eating disorder symptoms: The mediating role of affect regulation strategies. Personality and Individual Differences, 47(6), 662-667. DOI: 10.1016/j.paid.2009.06.006

Tolin, D. F. (2010). Is cognitive-behavioral therapy more effective than other therapies?: A meta-analytic review. Clinical Psychology Review, 30(6), 710-720. DOI: 10.1016/j.cpr.2010.05.003

Tor, P.-C., Bautovich, A., Wang, M.-J., Martin, D., Harvey, S. B., \& Loo, C. (2015). A Systematic Review and Meta-Analysis of Brief Versus Ultrabrief Right Unilateral Electroconvulsive Therapy for Depression. The Journal of Clinical Psychiatry. DOI: 10.4088/JCP.14r09145

Tse, W. S., \& Yip, T. H. J. (2009). Relationship among dispositional forgiveness of others, interpersonal adjustment and psychological well-being: Implication for interpersonal theory of depression. Personality and Individual Differences, 46(3), 365-368. DOI: 10.1016/j.paid.2008.11.001

Twenge, J. M., Martin, G. N., \& Campbell, W. K. (2018). Decreases in psychological well-being among American adolescents after 2012 and links to screen time during the rise of smartphone technology. Emotion, 18(6), 765-780. DOI: 10.1037/emo0000403

US Census Bureau. (2011). 2010 Census. Retrieved from http://www.census.gov/2010census/data/

Verduyn, P., Ybarra, O., Résibois, M., Jonides, J., \& Kross, E. (2017). Do Social Network Sites Enhance or Undermine Subjective WellBeing? A Critical Review. Social Issues and Policy Review, 11(1), 274-302. DOI: 10.1111/sipr.12033

Wampold, B. E., Minami, T., Baskin, T. W., \& Callen Tierney, S. (2002). A meta-(re)analysis of the effects of cognitive therapy versus "other therapies" for depression. Journal of Affective Disorders, 68(2-3), 159-165. DOI: 10.1016/S0165-0327(00)00287-1

Weaver A., Himle J.A., Taylor R., Matusko N.N., \& Abelson J.M. (2015). Urban vs rural residence and the prevalence of depression and mood 
disorder among african american women and non-hispanic white women. JAMA Psychiatry. DOI: 10.1001/jamapsychiatry.2015.10

Woodward, J. (2003). Making things happen: A theory of causal explanation. Oxford University Press.

- (2014). Methodology, ontology, and interventionism. Synthese, 123. DOI: $10.1007 / \mathrm{s} 11229-014-0479-1$

World Health Organization. (2019). Guidelines on physical activity, sedentary behaviour and sleep for children under 5 years of age. Retrieved from https://apps.who.int/iris/handle/10665/311664 